\title{
Safety Thickness Design of Horizontal Pillars under the Synergistic Effect of Upper and Lower Backfill
}

\author{
Zhang Wen ${ }^{1, *}$, Lian Minjie ${ }^{1}$, Chen Yu ${ }^{2}$, Liu Lang ${ }^{3}$, Shi Guangbin ${ }^{1}$ and KI-IL Song ${ }^{4}$ \\ ${ }^{1}$ College of Materials \& Mineral Resources, Xi'an University of Architecture and Technology, Xi'an 710055, China \\ ${ }^{2}$ School of Resources and Safety Engineering, Central South University, Changsha 410083, China \\ ${ }^{3}$ School of Energy Engineering, Xi'an University of Science and Technology, Xi'an 710054, China \\ ${ }^{4}$ Department of Civil Engineering, Inha University, Incheon 402-751, Korea
}

Received 2 August 2017; Accepted 29 October 2017

\begin{abstract}
Horizontal pillars are the main load-bearing elements in underground stopes. The stability of pillars directly influences the overall safety of mines, and their thickness directly affects the ore loss and the economy of mining. However, traditional design methods have shortcomings, such as shape simplification and the consideration of too few factors, which are not compatible with horizontal pillars in the filling method. An innovative method to accurately determine the safety thickness of irregular pillars under the filling condition was proposed in this study. First, the formula for calculating overlying backfill load to mine steeply inclined ore bodies was derived by analyzing the condition of irregular horizontal pillars. Support from the lower backfill body was considered further. A 3D numerical model of horizontal pillars that uses contact element was presented to study the effect of the maximum principal stress and the deflection on the pillar thickness. Finally, based on the maximal tension stress theory, the critical safety thickness with different safety factors was calculated, and the FLAC3D numerical simulation method was used to calculate the stability of mined-out areas on large-scale reserving horizontal pillars with safety thickness. Results show that the maximum tensile stress does not exceed the ultimate tensile strength of horizontal pillars under the critical safety thickness whose value obtained by the new method is smaller than the value calculated through the traditional design methods. In addition, deflections are restricted to an acceptable range. The pillars and stopes remain stable and massive destruction is not found. The validity and security of the safety thickness formed in the new design method were confirmed through the simulation experiment, which provide some reference and experience for the design of the safety thickness of horizontal pillars in similar mine sites by using the filling method.
\end{abstract}

Keywords: Horizontal pillar, Safety thickness, Upper and lower backfill, Contact model, Maximal tension stress theory

\section{Introduction}

During the course of high-level and large-scale filling and stoping, a horizontal slab mainly consisting of one ore body is established between two adjacent levels (i.e., horizontal pillar). The horizontal pillar can support the wall rock of upper and lower sides, relieve the upper ground pressure severely affecting deep stope, lower the disturbances to mining activities, and prevent the dynamic impact disaster of abrupt large-scale roof caving to the lower stope [1-4]. The thickness of a pillar is directly related to the safe production of mines because of its highly centralized stress. If the pillar is too thin, it is vulnerable to sudden collapse accidents, thus endangering both personnel and equipment safety. If the pillar is too thick, it is safe enough but it costs extra resources $[5,6]$.

Thickness and cross-ratio method, structural mechanics simplified beam method, Protodyakonovs theory, K. B. Lu Peinie theory, and load transfer method are traditional methods for designing the safety thickness of pillars [7-11].

*E-mail address: : zhangwen@xauat.edu.cn

ISSN: 1791-2377 @ 2017 Eastern Macedonia and Thrace Institute of Technology. All rights reserved. doi:10.25103/jestr.105.25
For example, Chang [12] determined the interlayer thickness from open-casting to underground mining by using the aforementioned mathematical and mechanical methods. Zhao [13] calculated and analyzed the appropriate size of isolated pillars using the methods of limit span mechanism, empirical equation, and limit equilibrium. The traditional methods for designing safety thickness through simplifying the load distribution are based on mathematical and mechanical theory to establish the model. However, traditional methods have several problems, such as the mechanics mechanism that fails to provide a full presentation of the practical situation accurately and consider different factors. The methods often over-calculate the safety thickness of pillars, leading to the enormous waste of ore body. Compared with traditional design methods, numerical modeling can take complicated load conditions, boundary conditions, and material property into consideration and correctly simulate the mechanical behavior of rock to obtain approximate solutions. Numerical modeling has become an efficient technique applied to determine the thickness of horizontal pillars and is widely used in mines. Singh et al. [14] discussed various applications of numerical modeling techniques to enhance the understanding on the mechanical response of strata management in mines. Georgieva et al. [15] created a 3D 
model of the crown pillar by using the specialized mining software Map3D and performed a detailed stress-strain state analysis in it. Kumar et al. [16] used finite element methods (FEM) to understand the behavior of crown and sill pillars and conducted the analyses with the results of 108 non-linear numerical models to design the crown pillar thickness. Numerical modeling is useful for designing the safety thickness of horizontal pillars under complex situations, such as an irregular shape. However, the previous models mainly focused on the load at the top of the pillar, taking the pillar as a simple model. The model is comprised of two parts: the horizontal pillar and its uniformly distributed load from the upper backfill or ore-rock. Safety thickness was calculated by numerical modeling methods, which did not conform to the actual situation of filling mining.

To eliminate the disadvantages of the above methods, an improved design method should be proposed based on the existing methods for determining the safety thickness of horizontal pillars in the backfill more accurately. Therefore, based on a comprehensive consideration of the irregular shape, complex geological environment, and stress condition, a finite element numerical analysis model of horizontal pillars under the synergistic effect of upper and lower backfill was proposed and the safety thickness was designed.

\section{State of the art}

As the comparatively weak element in a goaf, the collapse of the horizontal pillar, if it happens, links the upper and lower stopes, changes the legacy structure of the goaf, and causes serious local stress concentration, resulting in a large cave-in of the rock roof in the mined-out area $[17,18]$. Hence, the stability of the horizontal pillar plays a primary role in controlling the overall stability of a group of mined-out areas Many achievements have been realized to help determine the appropriate thickness and ensure safety in the production of deep mines. Bakhtavar et al. [5] introduced the relationship between dependent parameters and the crown pillar thickness and established a model to calculate the optimum pillar thickness in situations where a combined open-pit and block caving method is the most appropriate mining method. Palchik [19] studied the influence of physical characteristics of weak rock mass on the height of caved zones over abandoned subsurface coal mines and developed an empirical model to determine the height of a caved zone in weak porous rock mass over shallow, underground workings. Liu et al. [20] proposed the relationship model of the stability and the thickness-to-span ratio of the top pillar of the filling method transition stope with the $\pi$ theorems to analyze the stability of top pillars. The allowable strain of the top pillar was selected as the criterion of stope stability in the model. According to the allowable strain, the reasonable thickness-to-span ratio was obtained. The studies were mostly focused on the stability and safety thickness of crown pillars in the conversion of surface mining to underground or the transformation from block caving to stage backfill. By comparison, research on the safety thickness of horizontal pillars for the filling mining method is very few, as shown in Fig. 1.

The previous design of safety thickness mostly considered the pillar as a rectangular plate, which has some deficiencies and low accuracy, so the stability of the goaf was affected. Carter [21] used the critical scaled crown span for sizing crown thicknesses over a given stope for a range of rock mass quality characteristics as defined by the NGI-Q or geomechanics RMR classification systems. K.B. Lu [22] established the model of interval layers for the transition from open pit to underground mining based on the PU's equilibrium arch theory according to the principle of physical independence of forces. The methods indicated above have simple calculation, but most of them hypothesized the regularization in the shape of the pillar, a detail that failed to reflect the actual problem and considered the single factor. This failure limited the application to a great extent. In practical mining engineering, the reserved horizontal pillar is a classic irregular-shaped slab; many studies have been carried out on irregular slabs. Saadatpour and Azhari [23] presented a theoretical formulation for the static analysis of arbitrary quadrilateral-shaped plates based on the Galerkin method. Kang et al. [24] proposed a practical analytical method for the free vibration analysis of a simply supported polygonal plate with arbitrary shape by using the sub-domain method. However, according to the actual shape of a horizontal pillar, using irregular-shaped slabs to build a model construction analysis on safety thickness has not been studied. To avoid degradation in the accuracy of safety thickness brought upon by the simplification of the shape, the current study mainly aims to estimate the reasonable safety thickness of horizontal pillars in the backfill from the irregularly shaped plate model.

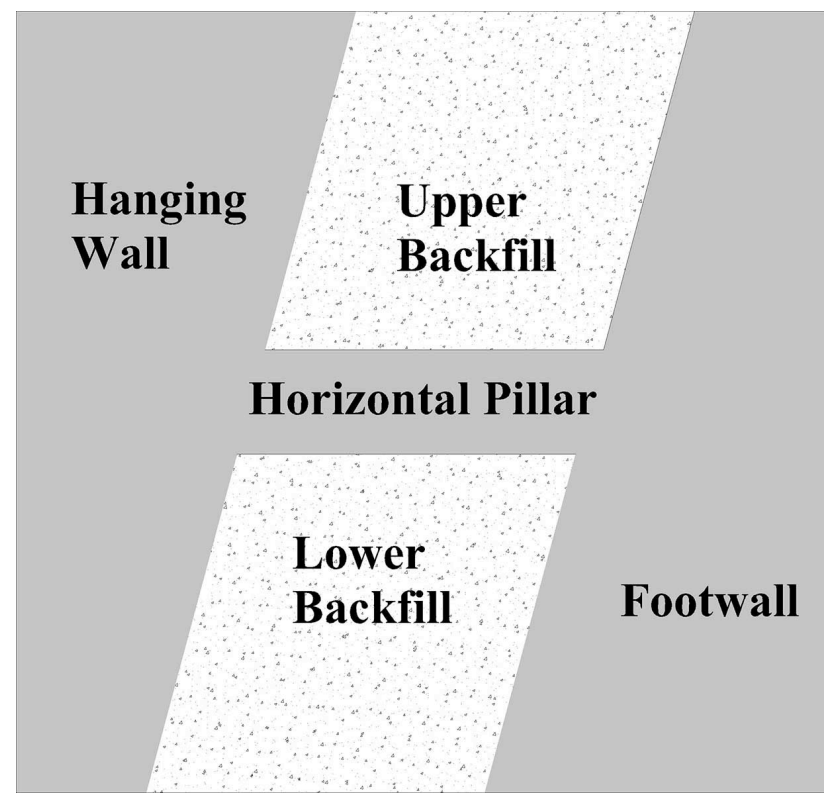

Fig. 1. Location of the horizontal pillar for the filling method

The existing studies on safety thickness also considered the horizontal pillar at loading state as a simple model comprising two parts: the uniformly distributed load from filling or ore and the pillar. For example, Guo et al. [25] simplified the load bearing above the entire coal pillar in a deep mine as saddle-shaped and researched coal pillar stability by using field measurement, 3D similar material simulation, numerical simulation, and theoretical analysis. Li et al. [26] calculated the minimum thickness of crown pillars on the basis of numerical modeling by integrating the usage of SURPAC and FLAC3D to beat at least $50 \mathrm{~m}$ at the Xinli Zone of the Sanshandao gold mine in the presence of a $10 \mathrm{~m}$ depth of sea water, 35 m-thick sea mud (silty clay), and Quaternary deposit in the seabed. During the filling mining, the backfill can be divided into upper and lower backfill 
depending on the locations of the horizontal pillars (Fig. 1). Hence, the loads acting on the horizontal pillars also comprise upper and lower backfill loads. These existing methods have been successfully applied to estimate upper load, but few studies have been concerned with the support and compatibility of deformation of the lower filling body. As understanding on the supporting force from the filling and the mechanism of the common action of filling and pillar increased, the study on the entire pillar state analysis in consideration of upper and lower filling body has attracted increased attention.

Therefore, in response to the problems and deficiencies of extant research, this study proposes a new method to estimate the safety thickness according to the structure parameters of stope, shape of horizontal pillar setting, and physical and mechanical parameters of rock and fill body. The method is based on Mindlin plate theory and Winkler foundation theory $[27,28]$. Combining contact face element, this approach establishes the finite element analysis model by considering the coordinated action of upper and lower backfill bodies. Moreover, it studies the change rules of the maximum principal stress, deflection with the thickness of horizontal pillar in a complex environment, and boundary conditions during high-bench mining. Subsequently, the maximum tensile stress criterion is applied to determine the reasonably horizontal pillar thickness, and the safety thickness of horizontal pillars is validated by FLAC3D. The achievements offer references to similar mine sites by using filling mining methods. Thus, the thickness can meet the safe exploitation demand, and greater economic benefit can be obtained.

\section{Methodology}

\subsection{Load acting on the horizontal pillar}

A typical cross section of a horizontal pillar in the backfill is shown in Fig. 1. The two zones of the backfill, namely, upper and lower backfill, are bounded by the horizontal pillar. According to the force analysis of the horizontal pillar, the loads on the pillar are composed of the filling loads and self-weight. Based on the classical Janssen bulk solid pressure theory, the upper backfill, which is assumed as composed of loose materials, acts on the horizontal pillar in the form of a uniformly distributed load under its own gravity [29]. However, the load on the top of the pillar cannot be computed according to the gravity of the backfill because of the ore body with dip angle, the friction force and cohesive force between the backfill body, and the surrounding rock wall. The mechanical model is established based on the actual bearing capacity. Furthermore, a calculation equation is deduced to calculate the vertical load on the top of the pillar.

To establish the mechanical model and deduce the calculation equation of the load, the following assumptions were made based on the characteristics of the mining method used in the mine: the backfill body comes into contact with the surrounding rock all around, $L$ is the strike length of the backfilled stope, $B$ is the width, $\alpha$ is the ore body dip, and $H$ is the total height of the backfill body. The geometric model is shown in Fig. 2a.

A thin-layer element of the backfill body in the horizontal direction may be analyzed, as shown in Fig. 2 b. The height of the thin-layer element is $d h$. The backfill body has a compacting effect on its surrounding rock under the action of the inside vertical stress $\sigma_{v}$. According to the law of action and reaction, the side walls of the backfill body bear a horizontal reacting stress $\sigma_{h}$ from the surrounding rock, that is, $\sigma_{h}=\lambda \sigma_{v}$, where $\lambda$ is the lateral pressure coefficient. The forces acting on the thin-layer element in the vertical direction are the shear force and the vertical force $F_{1}$ and $F_{2}$. The shear force acting on the thin-layer element consists of the friction force and the cohesive force between the surfaces of the backfill body and surrounding rock. The internal friction angle of the interface can be taken as the internal friction angle of the backfill body $\phi[30]$, the friction stress, that is, $f=\lambda \sigma_{v} \tan \phi$. The cohesion of the backfill $c$ is taken as an approximate value [31].

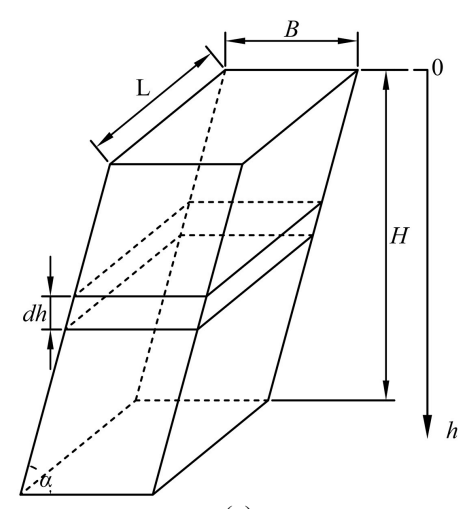

(a)
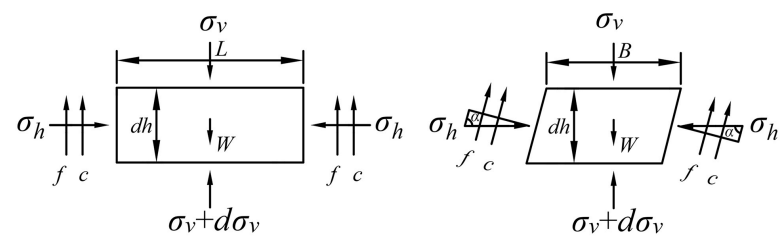

(b)

Fig. 2. Force diagram for the backfill body. (a) Geometric model of backfill body in the stage. (b) Force diagram for the horizontal microelement of the backfill body.

When the analysis of stress to the backfill of the thinlayer element is made, the weight of the backfill block is

$W=\gamma B L d h$

where $\gamma$ is the unit weight of the backfill.

The overlying force $F_{1}$ is

$F_{1}=\sigma_{v} B L$

The force upward $F_{2}$ from lower surface is

$F_{2}=\left(\sigma_{v}+d \sigma_{v}\right) B L$

The total driving force $F$ on the failure plane is

$F=\left(W+F_{1}-F_{2}\right) \sin \alpha=\left(\gamma B L d h-d \sigma_{v} B L\right) \sin \alpha$

The resisting force $T$ obtained from the surrounding wall rock is 


$$
\begin{aligned}
T= & 2\left(\lambda \sigma_{v} \sin \alpha \tan \phi+c\right) L d h / \sin \alpha+2\left(\lambda \sigma_{v} \tan \phi+c\right) B d h \\
& +W \cos \alpha \tan \phi
\end{aligned}
$$

If the backfill body does not fail, then the following condition must be satisfied: $F=T$.

According to the principle of force balance, the vertical mechanical balance equation of the thin layer can be obtained:

$$
\begin{aligned}
d \sigma_{v} B L \sin \alpha= & {\left[\gamma B L \sin \alpha\left(1-\frac{\tan \phi}{\tan \alpha}\right)-2 \lambda \sigma_{v} \tan \phi(B+L)\right.} \\
& -2 c(L / \sin \alpha+B)] d h
\end{aligned}
$$

By solving Eq. (6), the following expression can be derived:

$$
\begin{aligned}
& -\frac{2 \lambda \tan \phi(B+L)}{B L \sin \alpha} h= \\
& \ln \left[1-\frac{2 \lambda \tan \phi(B+L)}{\gamma B L \sin \alpha\left(1-\frac{\tan \phi}{\tan \alpha}\right)-2 c(L / \sin \alpha+B)} \sigma_{v}\right]+C
\end{aligned}
$$

where $C$ is the constant determined by boundary conditions.

When the moment that the backfill body in the upper level cannot bear the compressive stress from the overburden rock after roof contact is considered, the height of the backfill $(h)$ is zero, , and the constant $C$ is zero.

When rearranged, the vertical stress of backfill is

$$
\sigma_{v}=\frac{\gamma B L \sin \alpha\left(1-\frac{\tan \phi}{\tan \alpha}\right)-2 c(L / \sin \alpha+B)}{2 \lambda \tan \phi(B+L)}\left(1-e^{-\frac{2 \lambda \tan \phi(B+L)}{B L \sin \alpha} h}\right)
$$

Equation (8) indicates that as the cohesion emerges, the value of the strength of the backfill body decreases. For the safety of mining and simple calculation, the cohesion between the backfill body and the surrounding rock $(c)$ is 0 . At this point, the vertical stress $\sigma_{v}$, (i.e., the overlying load

$q_{z}$ ) can be simplified to

$$
q_{z}=\frac{\gamma B L \sin \alpha\left(1-\frac{\tan \phi}{\tan \alpha}\right)}{2 \lambda \tan \phi(B+L)}\left(1-e^{-\frac{2 \lambda \tan \phi(B+L)}{B L \sin \alpha} h}\right)
$$

\subsection{Mechanical model of the horizontal pillar}

The thickness of the horizontal pillar $T$ is affected by two main factors: the pillar itself, including the shape, size, and mechanical parameters; and the pillar's existing environment, including the position, overlying load, and supported conditions [32]. Based on site survey, taking Stope 6\# on the level $320 \mathrm{~m}$ in LI Guanji iron mine, Shandong Province, China, for example, the existing condition of Pillar 6\# is shown in Fig. 3a. The side AB and side $\mathrm{CDE}$ of the pillar are surrounded by wall rocks, with the side $\mathrm{AE}$ and side $\mathrm{BC}$ flanked by barrier pillars. The pillar can be considered an elastic plate with four sides having completely clamped support and ignoring the cracks of the ore body. The overlying load from the upper backfill body on the level $-220 \mathrm{~m}$ is $q_{z}$, the weight of the pillar is $\rho g T$, and the reaction force from the lower backfill body acts on the base of pillar, as shown in Fig. $3 b$.

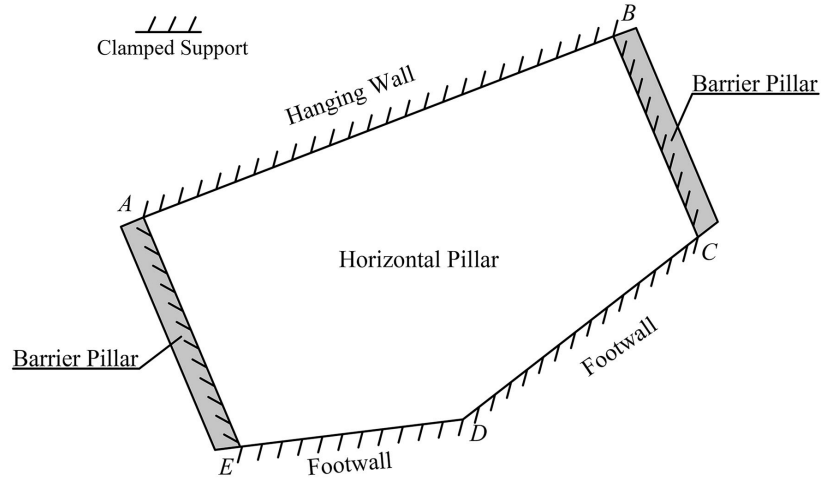

(a)

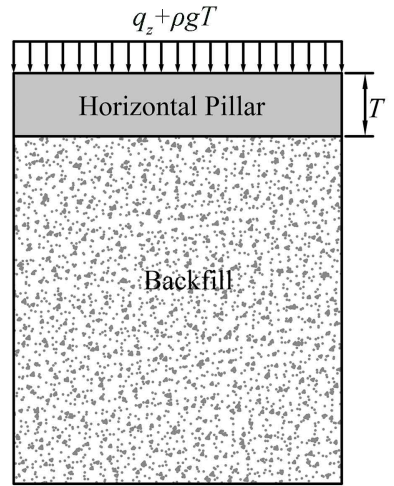

(b)

Fig. 3. Mechanical model for the horizontal pillar. (a) Schematic plan view of mechanical model. (b) Schematic vertical cross section.

\subsection{Finite element models}

\subsubsection{Selection of analysis model}

ANSYS is widely applied in many fields, including underground mining. It can be used to design the thickness of horizontal pillars. Choosing the proper analysis model to design the thickness of the pillars is a very important task. It has a direct influence not only on the reaction distribution of the lower backfill body but also on the stress and deformation distribution of the pillar [33, 34]. The horizontal pillar is established between two levels. The overlying uniform load is applied by the backfill body from the upper level, and the lower backfill body reacts on the base of the pillar. Based on the theory of elastic plate with rapid development in recent decays, the quantitative model is established to analyze internal mechanical responses according to the load condition and environment factors. The pillar has considerable stiffness, which can be modeled as an elastic plate with minimal deflection supported on an elastic foundation. The shell element is applied to carry out the FEM spatial analysis of structure, with the merits of having significantly less number of nodes and convenient implementation. It is more likely to be accepted, making it suitable for various types of plate, thin or with a certain thickness. The lower backfill body can be regarded as the monolayer elastic homogenous foundation with solid elements used for simulation. The types of materials can be chosen to build a finite element mechanical model according 
to actual needs, such as homogeneous linear elastic model, homogeneous elastic-plastic model, and layered homogeneous elastic-plastic model $[35,36]$.

\subsubsection{Finite element calculation based on plate theory}

To guarantee accuracy, the numerical simulations were conducted based on the Mindlin moderately thick plates with unknown thickness [27, 28, 37]. The in-plane deflection $\omega(x, y)$ and the rotations of surface normal $\theta_{x}(x, y)$, $\theta_{y}(x, y)$ were adopted as nodal displacements [38]. The potential energy functional of the horizontal pillar was obtained as follows:

$$
\Pi=\frac{1}{2} \iint\{\varepsilon\}^{T}[D]\{\varepsilon\} d x d y-\iint(q-p) \omega d x d y-\int\{\bar{u}\}\{\bar{F}\} d s
$$

where $q$ is the overlying load, $p$ is the contact pressure, $\{\varepsilon\}$ is the strain matrix, $[D]$ is the geometry stiff matrix, $\{\bar{u}\}$ is the displacement matrix, and $\{\bar{F}\}$ is the load matrix.

When the plate is simulated by utilizing the finiteelement method, finite element grids are generated and each node displacement in the deformable block is marked. When the principle of minimum potential energy and Eq. (10) are combined, the interactive governing equation between pillar and backfill body is obtained:

$\left(\left[K_{b}\right]+\left[K_{s}\right]\right)\{\Delta\}=\{F\}$

where $\left[K_{b}\right]$ is the general stiffness matrix for the pillar, $\left[K_{s}\right]$ is the stiffness matrix for the backfill body, $\{\Delta\}$ is the nodal displacement matrix, and $\{F\}$ is the nodal load matrix.

The internal forces of the horizontal pillars can be obtained based on Eqs. (10) and (11).

\section{Result analysis and discussion}

\subsection{Study area}

The remainder of this paper adopts the new finite element numerical analysis model to determine the safety thickness of horizontal pillars under the synergistic effect of upper and lower backfill with the case of LI Guanji iron mine.

\subsubsection{Engineering geological conditions of LI Guanji iron mine}

LI Guanji iron mine is located at Guocang Township, $86 \mathrm{~km}$ away from Mount Tai, Shandong Province, China. The mine and the surrounding areas are fertile land with a flat topography. The ore body is distributed in 14 layers, and the depth is from $0 \mathrm{~m}$ to $600 \mathrm{~m}$. The length along the strike of the main ore body is $1365 \mathrm{~m}$, and the average SE-direction dip angle is $75^{\circ}$. The ore body is composed of banded magnetite amphibole quartzite and the roof and floor of biotite granulite, which is moderately stable. The boundary between the ore body and the surrounding rock is indistinct. The upward horizontal slice stope-filling method with pointed pillars is a common mining method adopted in this mine. The stopes are arranged along the strike of the ore body within the width of the horizontal thickness. The lengths vary from $60 \mathrm{~m}$ to $120 \mathrm{~m}$, depending on the changes in thickness of the ore body. The height of the stage stope is approximately $100 \mathrm{~m}$. The width of the interval pillars between stopes is $6 \mathrm{~m}$, as shown in Fig. 4. Meanwhile, some methods such as pillar setting in stope and full-tailings backfill are utilized to avoid the collapse of farmlands and buildings on the surface because of mining activity. To reduce the filling cost, the tailings-consolidated backfill is used in the mine, and various cement sand ratios are used at different heights. The cement-tailing ratio of the cemented layer is $1: 6$ at the top of $1 \mathrm{~m}$ of each layer as the work platform used for the next operation cycle. The cementtailing ratio of the other parts is $1: 12$, and the total of the backfill height of each layer is $6 \mathrm{~m}$. Table 1 lists the adjusted physico-mechanical parameters of ore body and backfill as obtained from job site sampling analysis and laboratory rock mechanical testing.

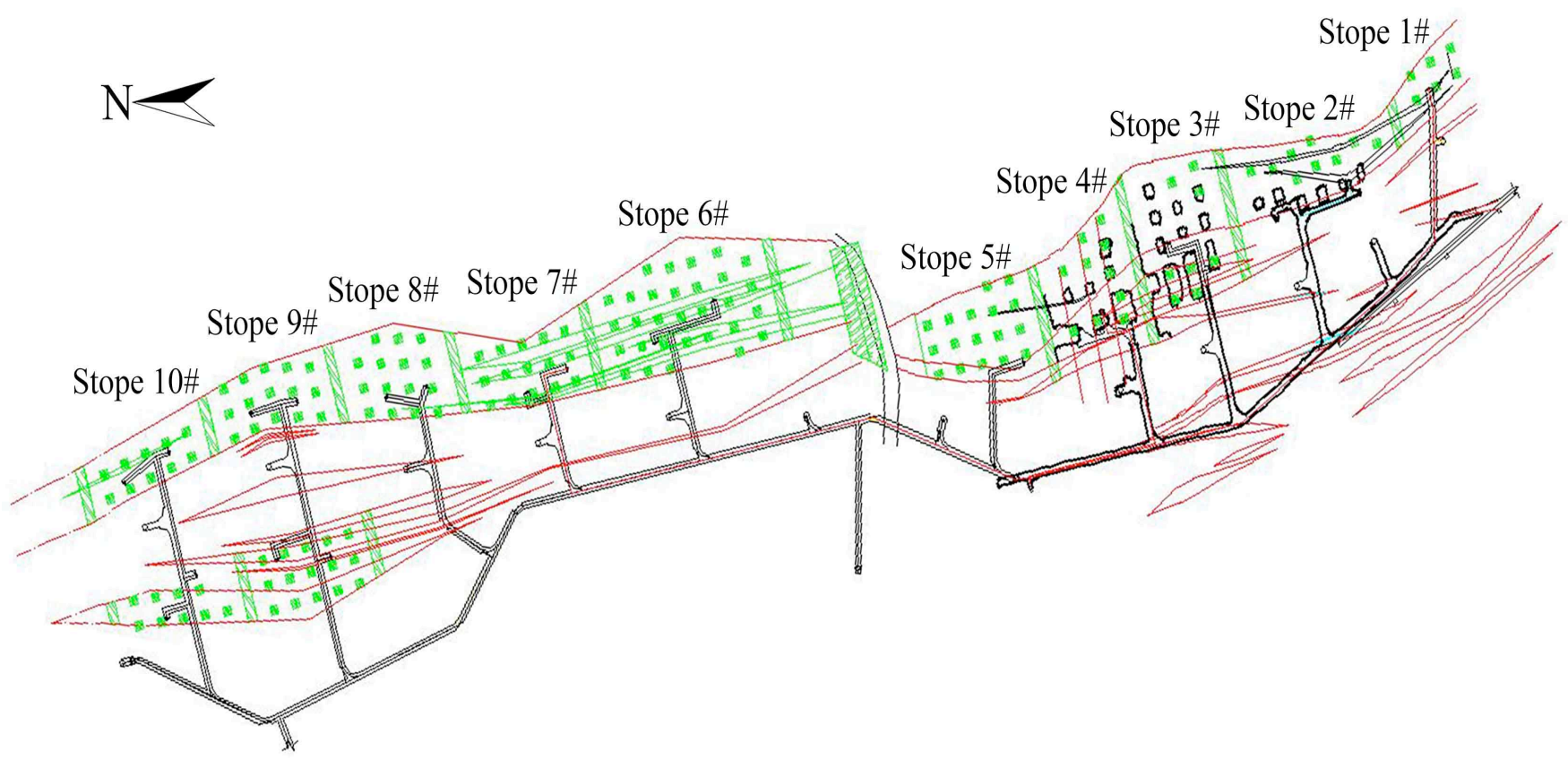

Fig. 4. The layout plan of stopes on level -320 $\mathrm{m}$ in LI Guanji iron mine 
Table 1. The basic physical parameters of ore-rock and backfill in Li Guanji iron mine

\begin{tabular}{|c|c|c|c|c|c|c|}
\hline Type & Density $\left(\mathrm{kg} / \mathrm{m}^{3}\right)$ & $\begin{array}{l}\text { Elastic } \\
\text { modulus (Gpa) }\end{array}$ & Poisson's ratio & $\begin{array}{l}\text { Cohesion } \\
\text { (Mpa) }\end{array}$ & $\begin{array}{l}\text { Friction } \\
\text { angle }\left(^{\circ}\right)\end{array}$ & $\begin{array}{l}\text { Tensile } \\
\text { strength (Mpa) }\end{array}$ \\
\hline Quaternary system & 1950 & 0.05 & 0.35 & 0.10 & 23 & / \\
\hline Ore body & 3300 & 23.52 & 0.23 & 6.02 & 34 & 6.40 \\
\hline biotite granulite (hanging wall) & 2793 & 22.19 & 0.25 & 2.38 & 35 & 2.56 \\
\hline biotite granulite (footwall) & 2830 & 19.07 & 0.23 & 1.86 & 37 & 2.18 \\
\hline Backfill (1:6) & 2000 & 1.00 & 0.25 & 0.55 & 33 & 0.50 \\
\hline Backfill (1:12) & 1900 & 0.75 & 0.23 & 0.42 & 31 & 0.30 \\
\hline
\end{tabular}

\subsubsection{Structural pattern survey of horizontal pillars}

The main ore body on level $-320 \mathrm{~m}$ in LI Guanji iron mine is divided into 10 stopes by the interval pillars. One stope is allocated a horizontal pillar, numbered $1 \#$ through $10 \#$, as shown in Fig. 4. The pillar shape is close to an irregular quad and ranges from $59.79 \mathrm{~m}$ to $124.26 \mathrm{~m}$ in length along the strike, which is $1749.28-8245.80 \mathrm{~m}^{2}$. The design parameters of the 10 pillars are listed in Table 2. The position and distribution of loads change with the shape and dimension of the pillars. The design of safety thickness has some deficiencies according to a certain uniform shape, which affects the stability of the goaf. Hence, to design the reasonable thickness, the FEM models of the horizontal pillars with differences in the shape are developed respectively through the survey of the structure parameters of the 10 stopes.

Table 2. The size and overlying load of the horizontal pillars

\begin{tabular}{|c|c|c|c|c|c|c|c|}
\hline \multirow{2}{*}{ Pillar } & \multirow{2}{*}{ Area $\left(m^{2}\right)$} & \multicolumn{4}{|c|}{ Strike length $L(\mathrm{~m})$} & \multirow{2}{*}{$\begin{array}{c}\text { Average width B } \\
\text { (m) }\end{array}$} & \multirow{2}{*}{$q_{z}$ (MPa) } \\
\hline & & East & West & Middle & Average & & \\
\hline $1 \#$ & 1749.28 & 61.59 & 59.73 & 58.05 & 59.79 & 29.26 & 0.76 \\
\hline $2 \#$ & 4036.81 & 114.69 & 114.74 & 115.42 & 114.95 & 35.12 & 0.91 \\
\hline $3 \#$ & 5501.51 & 64.06 & 64.18 & 64.01 & 64.08 & 85.85 & 1.04 \\
\hline 4\# & 4208.58 & 71.24 & 62.47 & 65.94 & 66.55 & 63.24 & 0.99 \\
\hline $5 \#$ & 4341.52 & 80.59 & 81.02 & 82.77 & 81.46 & 53.30 & 0.99 \\
\hline $6 \#$ & 8245.80 & 124.27 & 124.29 & 124.22 & 124.26 & 66.36 & 1.11 \\
\hline $7 \#$ & 3774.31 & 86.14 & 86.50 & 86.30 & 86.31 & 43.73 & 0.94 \\
\hline $8 \#$ & 3965.52 & 76.73 & 76.88 & 77.03 & 76.88 & 51.58 & 0.97 \\
\hline 9\# & 3301.26 & 84.33 & 84.04 & 84.14 & 84.17 & 39.22 & 0.90 \\
\hline $10 \#$ & 2830.44 & 86.76 & 86.36 & 86.55 & 86.56 & 32.70 & 0.85 \\
\hline
\end{tabular}

\subsubsection{Calculation of the overlying backfill load}

The expected mining height is $100 \mathrm{~m}$ on the level $-220 \mathrm{~m}$ above the horizontal pillars in LI Guanji iron mine. The cement-tailing ratio of the upper backfill body is $1: 12$, and the value of lateral pressure coefficient $\lambda$ is 0.274 . When related mechanical parameters (4.1.1) and design parameters of stopes (4.1.2) (i.e., Table 1 and Table 2) are substituted into Eq. (9), the overlying load on the horizontal pillars can be obtained, as shown in Table 2 .

\subsection{Construction of finite element models}

Based on the analysis above, the finite element models of the horizontal pillars in the backfill body were built using ANSYS finite element analysis program. The horizontal pillars were modeled with SHELL 181 elements, which are suitable for analyzing shell structures from thin to moderately thick. The element is a four-node element with six degrees of freedom at each node (i.e., translations in the $x, y$, and $z$ directions), and rotations about the $x, y$, and $z$ axes. To improve the computational efficiency, a simplified simulated model for the lower backfill body was established. The layered backfills were simplified into a $90 \mathrm{~m}$-high backfill body, with horizontal constraints around and a vertical constraint on the bottom, as shown in Fig. 5. The backfill body was modeled by SOLID 185 eight-node brick element. The element was defined by eight nodes having three degrees of freedom at each node (i.e., translations in the nodal $x, y$, and $z$ directions). The cement-tailing ratio of the lower backfill body was set as 1:12. The computational parameters of the pillar and the upper backfill body were chosen in accordance with the actual situation listed in Tables 1 and 2.

The contact pairs were used to simulate the interaction between the pillar and the lower backfill body, as shown in
Fig. 5. The interaction between pillar and backfill was transmitted through contact elements. The contact pairs were composed of target element (TARGE) and contact element (CONTA). The target element was attached on the upper surface of the backfill body with the corresponding deformed body's boundary, and the contact element was attached on the lower surface of the horizontal pillar. The normal stress and shear stress were obtained after the contact, and the relative glide trend obeyed Coulomb's rule. The finite element analysis models were built. The meshed model of horizontal pillar and backfill body in Stope 6\# is shown in Fig. 5, which depicts the loading and boundary conditions. The meshing of the complete model produced an average of 3,614 eight-node quad elements and 3,756 nodes.

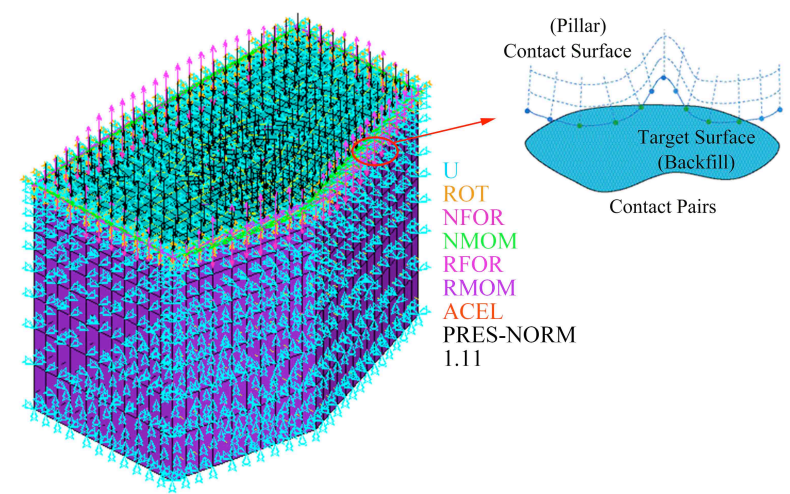

Fig.5. FEM analysis model for the horizontal pillar

\subsection{Analysis of the finite element modeling results}

Finite element analysis of the stability of the horizontal pillar was performed to design the reasonable thickness and ensure the safe exploitation. Based on the previous section, the 
finite element models of pillars in different thickness were built under the conditions of 10 stopes in LI Guanji iron mine. A total of 90 simulations using 10 different computer models in different thickness were conducted, and the results of finite element models were analyzed in terms of stresses and deflections in the pillars. Based on these results, the relationship between thickness and parameters was determined by using a multiple regression analysis technique.

\subsubsection{Relationship between thickness and stress}

The maximal principal stresses on the upper and lower surface of horizontal pillars in different thicknesses are

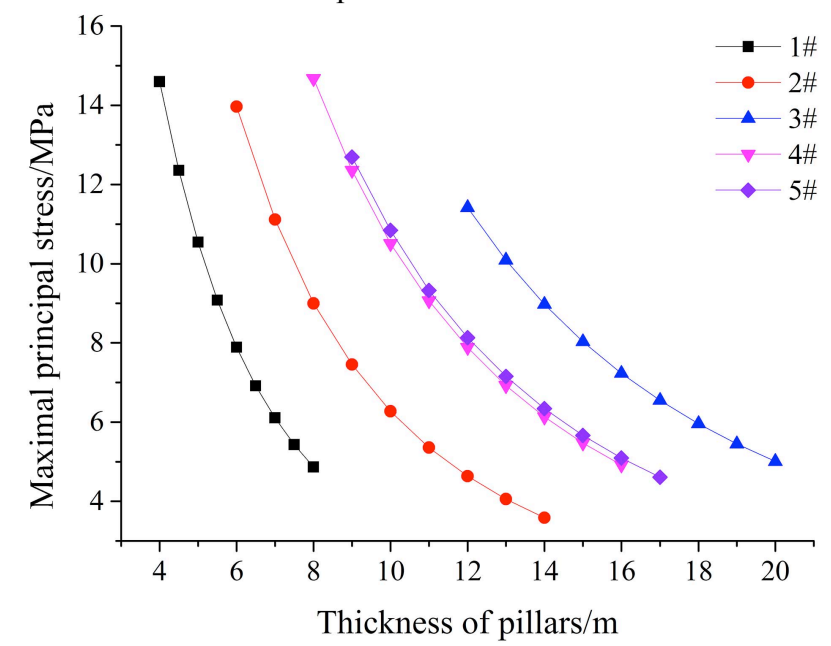

(a) shown in Figs. 6 and 7, respectively. The maximum principal stress on the upper surface is tensile stress, with the largest tensile stress appearing at the connection between pillar and surround wall, as shown in Fig. 9a. The maximum principal stress on the lower surface is also tensile stress, but with the maximum value placed in the central part of the pillar. As the thickness of the pillar increases, the maximum principal stress decreases and the reduction range levels off (Figs. 6 and 7). The decrease of the maximum principal stress is smooth as the thickness increases.

Fig. 6. Maximum principal stress on the upper surface of horizontal pillars in different thicknesses. (a) Pillars $1 \# \sim 5 \#$. (b) Pillars $6 \# \sim 10 \#$.

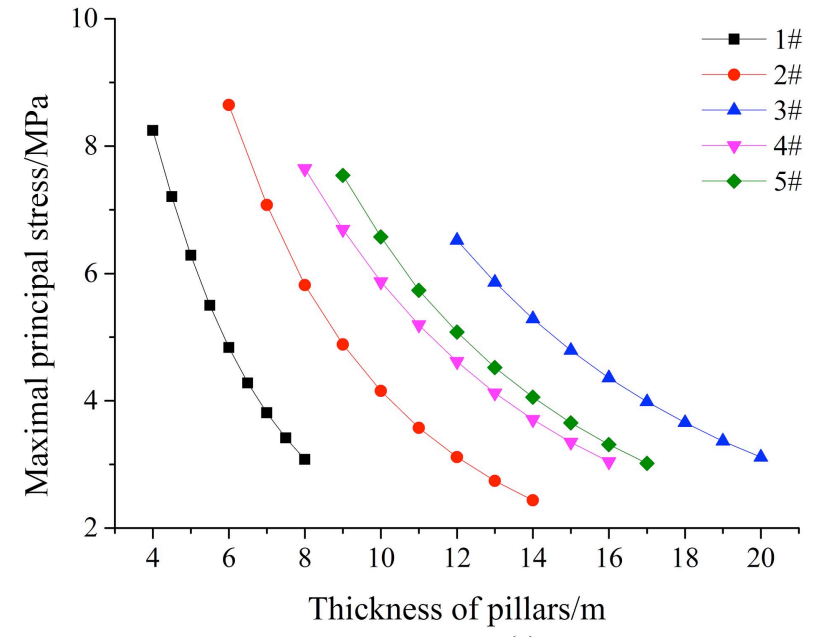

(a)

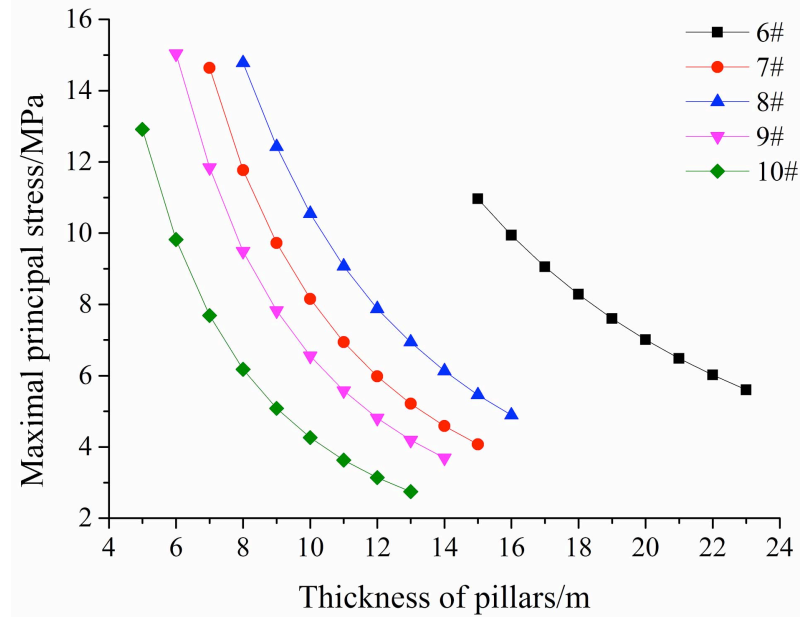

(b)

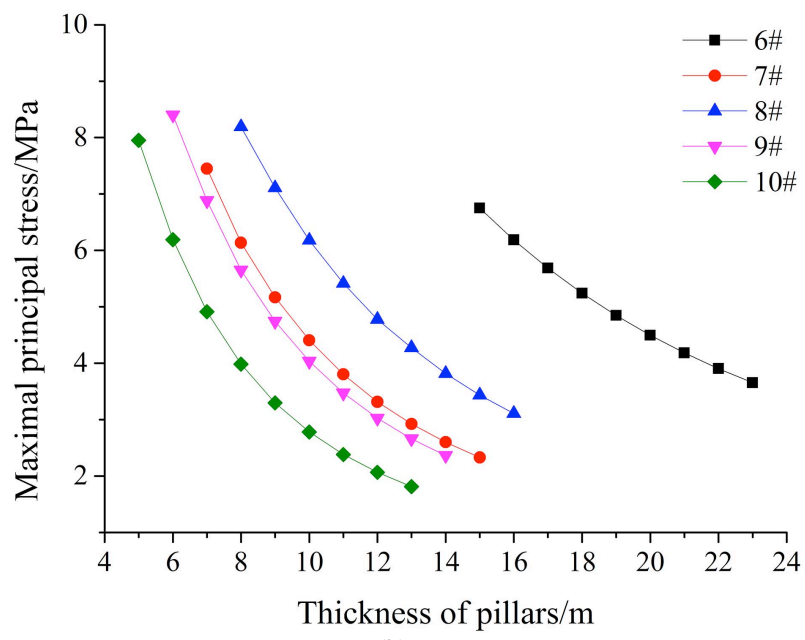

(b)

Fig. 7. Maximum principal stress on the lower surface of horizontal pillars in different thicknesses . (a) Pillars 1\# 5\#. (b) Pillars 6\# 10\#.

To further study the variation of the maximum principal stress with the thickness, the response curves of the thickness and maximum principal stress were fitted by linear function, polynomial function, and power function, respectively. The multiple correlation coefficients $R^{2}$ of the thickness and maximal principal stress on the upper surface were obtained, as shown in Table 3.

Table 3. Multiple correlation coefficients $\left(R^{2}\right)$ of thickness and maximal principal stress

\begin{tabular}{|c|c|c|c|c|c|c|c|c|c|c|c|}
\hline $\begin{array}{c}\text { Fitting } \\
\text { type }\end{array}$ Pillar & $1 \#$ & $2 \#$ & $3 \#$ & 4\# & $5 \#$ & $6 \#$ & $7 \#$ & $8 \#$ & 9\# & $10 \#$ & Average \\
\hline $\begin{array}{l}\text { Linear } \\
\text { Polynomial } \\
\text { Power }\end{array}$ & $\begin{array}{l}0.967 \\
0.999 \\
0.997\end{array}$ & $\begin{array}{l}0.917 \\
0.995 \\
0.999\end{array}$ & $\begin{array}{l}0.969 \\
0.999 \\
0.999\end{array}$ & $\begin{array}{l}0.947 \\
0.998 \\
0.999\end{array}$ & $\begin{array}{l}0.953 \\
0.998 \\
0.999\end{array}$ & $\begin{array}{l}0.979 \\
0.999 \\
0.999\end{array}$ & $\begin{array}{l}0.926 \\
0.996 \\
0.999\end{array}$ & $\begin{array}{l}0.946 \\
0.998 \\
0.999\end{array}$ & $\begin{array}{l}0.912 \\
0.994 \\
0.999\end{array}$ & $\begin{array}{l}0.894 \\
0.992 \\
0.999\end{array}$ & $\begin{array}{l}0.941 \\
0.997 \\
0.999\end{array}$ \\
\hline
\end{tabular}


From the value of the multiple correlation coefficients, the maximal principal stress of pillars with thicknesses varied nonlinearly. The relationship can be better fitted by polynomial function and power function. The value of multiple correlation coefficients reached 0.99 , and the average of the correlation coefficient with power fitting was above 0.999 . The power function can more clearly explain the relationship between the maximal principal stress and the thickness. In conclusion, the maximal principal stress of pillars has a clear decreasing trend as the thickness increases and follows a nonlinear function. Therefore, it is possible to formulate the maximum principal stress $\sigma_{1 \max }$ with the thickness as follows:

$\sigma_{1 \max }=a_{1} T^{-b_{1}}$

where $\sigma_{1 \max }$ is the maximal principal stress on the upper surface of the horizontal pillar. The parameters $a_{1}$ and $b_{1}$ depend on the size of the pillar, the overlying load, and the lower backfill body.

\subsubsection{Relationship between thickness and deflection}

Two diagrams of the maximal deflection of horizontal pillars in different thicknesses were constructed based on the simulation analysis data of 10 pillars (Figs. 8a and 8b). As shown in Fig. 8, the pillars were sunken under the overlying load and its gravity action. The lesser the pillar thickness was, the greater the effect on the pillar deformation. The maximal deflection decreased with the increase in thickness. The decrease of deflection was smooth as the thickness increased. Hence, the deflection decreases along with the increase in thickness, but the decrease is limited.

\subsection{Safety thickness design based on the maximum tensile stress criterion}

The horizontal pillar shows different destructive phenomena and destructive forms under the effect of different mine geological conditions and stress conditions. To guarantee the stability of the horizontal pillars, an analytical research should be conducted according to the concrete mining conditions, and the criterion should be chosen appropriately. The mine geological conditions and stress conditions are different, as well as the destructive phenomenon and destructive forms on the pillar. In an actual project, the horizontal pillars are established between the upper and lower backfill bodies, contributing to isolating the two levels, avoiding cavity expansion, and diminishing the stress intensity. The pillar is at the top of the lower level, which is equivalent to the roof. It must be complete and cannot suffer bent and tensile damage. Therefore, this study used the maximum tensile stress criterion to determine the safety thickness of the horizontal pillars.

According to the numerical simulation result, the regression analysis was conducted on the relationship between deflection and thickness. The pillar thickness exhibited a power function of the deflection with the value of multiple correlation coefficients reaching 0.998. In addition, the following equation could be obtained:

$$
d_{\max }=a_{2} T^{-b_{2}}
$$

where $d_{\max }$ is the maximal deflection. The parameters $a_{2}$ and $b_{2}$ depend on the size of the pillar, the overlying load, and the lower backfill body.

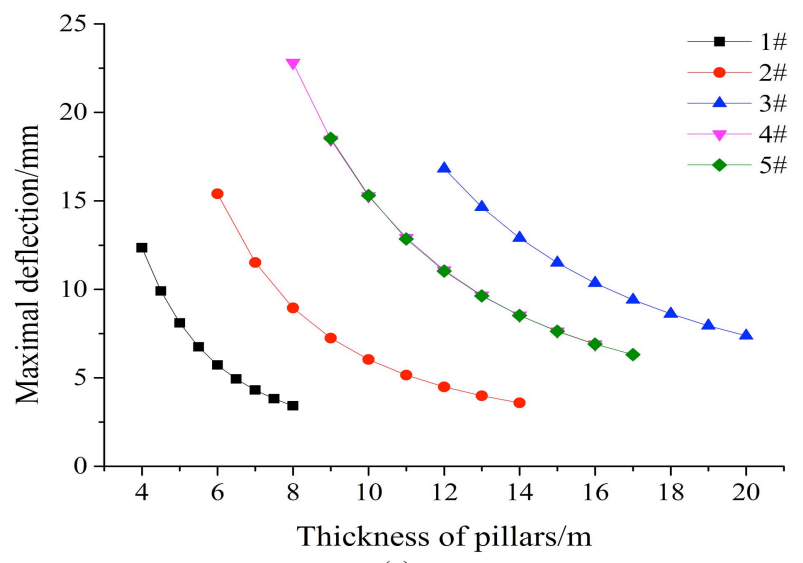

(a)

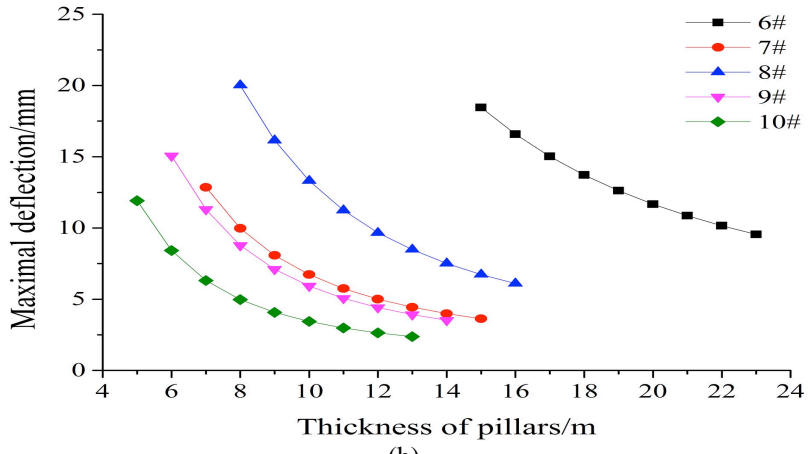

(b)

Fig. 8. Maximal deflection of horizontal pillars in different thicknesses. (a) Pillars 1 5\#. (b) Pillars 6 10\#.

The maximum tensile stress criterion is as follows: if the tensile stress $\sigma_{t}$ that acts on the rocks exceeds its intensity $\left[\sigma_{t}\right]$, then bending tensile failure happens. The subsidence of pillars due to its self-weight and overlying load causes tensile failure on the surface. Therefore, ensuring that the maximal principal stress on the surface of horizontal pillars is considerably lower than the tensile strength of the ore body is crucial. The safety thickness of the horizontal pillars ( $T_{f}$ ) based on the Mohr-Coulomb yield criterion and considering the safety factor $(f)$ is as follows:

$\sigma_{1 \max }\left(T_{f}\right) \leq\left[\sigma_{t}\right] / f$

where $\sigma_{1 \max }\left(T_{f}\right)$ is the maximum tensile stress of the pillar with the thickness $T_{f}$, and $\left[\sigma_{t}\right]$ is the ultimate tensile strength.

Combined with the results of finite element numerical analysis, the safety thickness $\left(T_{f}\right)$ of the 10 pillars in level $320 \mathrm{~m}$ in LI Guanji iron mine can be obtained through Eqs. (12) and (14) for the given safety factors. For the detailed data, see Table 4. 
Table 4. Minimum thickness of horizontal pillars under different safety factors

\begin{tabular}{|c|c|c|c|c|c|c|c|c|c|}
\hline \multirow{2}{*}{ Pillar } & \multirow{2}{*}{$\operatorname{Area}\left(\mathbf{m}^{2}\right)$} & \multirow{2}{*}{$\begin{array}{l}\text { Average } \\
\operatorname{span}(\mathbf{m})\end{array}$} & \multirow{2}{*}{$\begin{array}{l}\text { Average } \\
\text { width (m) }\end{array}$} & \multirow{2}{*}{$\begin{array}{l}\text { Overlying } \\
\text { load (MPa) }\end{array}$} & \multicolumn{5}{|c|}{ Critical safety thickness $T_{f}$ (m) } \\
\hline & & & & & 1.0 & 1.2 & 1.4 & 1.6 & 1.8 \\
\hline $\begin{array}{l}1 \# \\
2 \# \\
3 \# \\
4 \# \\
5 \# \\
6 \# \\
7 \# \\
8 \# \\
9 \# \\
10 \# \\
\text { Maximum }\end{array}$ & $\begin{array}{l}1749.28 \\
4036.81 \\
5501.51 \\
4208.58 \\
4341.52 \\
8245.80 \\
3774.31 \\
3965.52 \\
3301.26 \\
2830.44 \\
8245.80\end{array}$ & $\begin{array}{l}59.79 \\
114.95 \\
64.08 \\
66.55 \\
81.46 \\
124.26 \\
86.31 \\
76.88 \\
84.17 \\
86.56 \\
124.26\end{array}$ & $\begin{array}{l}29.26 \\
35.12 \\
85.85 \\
63.24 \\
53.30 \\
66.36 \\
43.73 \\
51.58 \\
39.22 \\
32.70 \\
85.85\end{array}$ & $\begin{array}{l}0.76 \\
0.91 \\
1.04 \\
0.99 \\
0.99 \\
1.11 \\
0.94 \\
0.97 \\
0.90 \\
0.85 \\
1.11\end{array}$ & $\begin{array}{l}6.83 \\
9.88 \\
17.45 \\
13.70 \\
14.07 \\
21.33 \\
11.54 \\
13.82 \\
10.17 \\
7.78 \\
21.33 \\
\end{array}$ & $\begin{array}{l}7.66 \\
11.06 \\
19.55 \\
15.37 \\
15.78 \\
23.96 \\
12.86 \\
15.50 \\
11.35 \\
8.70 \\
23.96\end{array}$ & \begin{tabular}{l|}
8.44 \\
12.17 \\
21.51 \\
16.95 \\
17.39 \\
26.43 \\
14.09 \\
17.08 \\
12.45 \\
9.57 \\
26.43
\end{tabular} & $\begin{array}{l}9.17 \\
13.23 \\
23.37 \\
18.44 \\
18.92 \\
28.78 \\
15.26 \\
18.57 \\
13.50 \\
10.38 \\
28.78\end{array}$ & $\begin{array}{l}9.88 \\
14.23 \\
25.14 \\
19.87 \\
20.37 \\
31.02 \\
16.37 \\
20.00 \\
14.49 \\
11.16 \\
31.02\end{array}$ \\
\hline
\end{tabular}

As shown in Table 4, when the safety factor is 1.0, the maximal principal stress on the upper surface of horizontal pillars is exactly equal to the tensile strength of the pillar, and the minimum thicknesses of horizontal pillars range from $6.83 \mathrm{~m}$ to $21.33 \mathrm{~m}$. The average thickness is $12.66 \mathrm{~m}$. Then, for each 0.2 increase in the safety factor $f$, the average thickness of the pillars increases by $1.40 \mathrm{~m}$. According to the analyzed result above, a strong relationship also exists between the thickness of the pillars and the size of the exposed roof. The approximate rule is that the larger the exposed area, the larger the thickness of the pillar; however, this is not an absolute correlation, such as in the case of Pillar $8 \#$ and Pillar 2\#. The exposed area of Pillar $8 \#$ is smaller than that of Pillar 2\#, but the calculated thickness of Pillar $8 \#$ is relatively larger, which is contrary to the rule. An observation of the two pillars reveals that the shape of Pillar $8 \#$ is relatively normal and Pillar $2 \#$ is complex. The lengthwidth ratio of Pillar $8 \#$ is less than Pillar 2\#. In conclusion, the thickness of horizontal pillars is affected both by the exposed area and its shape.

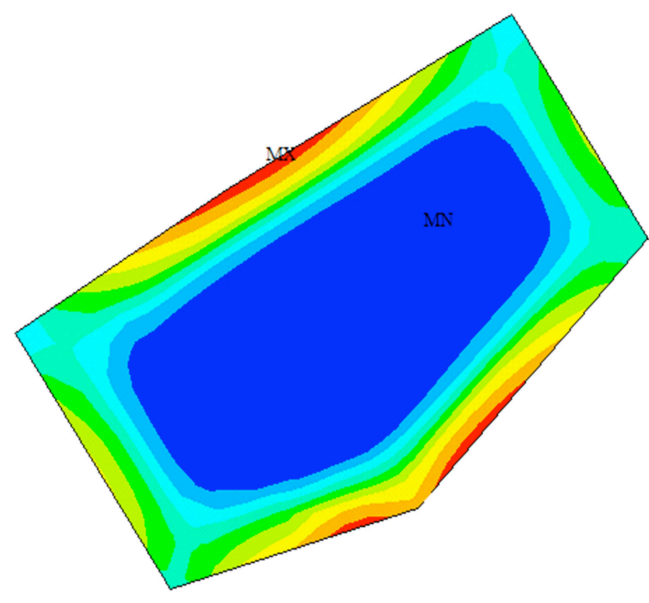

(a)

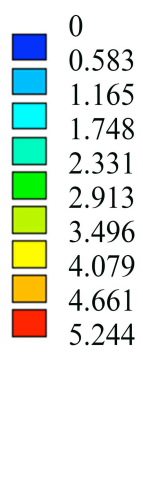
0.583 1.165 1.748 2.331 2.913 3.496 4.079 4.661 5.244

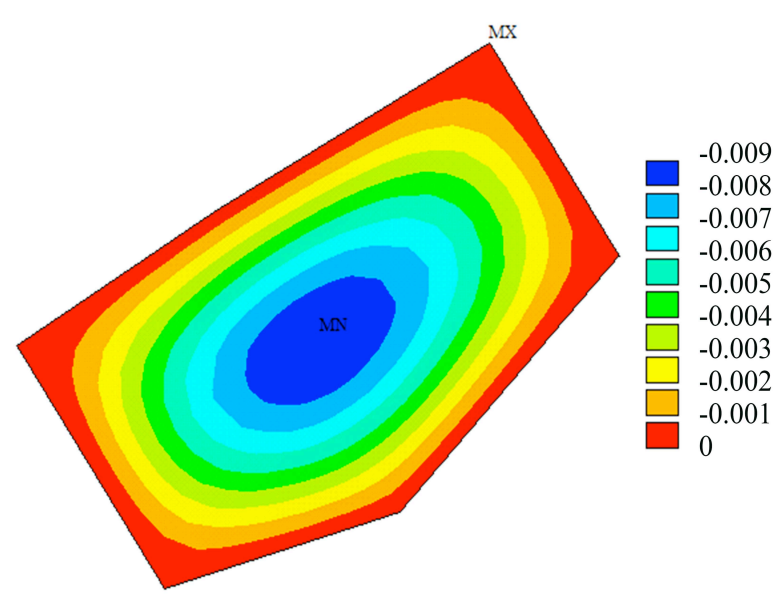

(b)

Figure.9. Maximum principal stress and deflection distribution of Pillar 6\#. (a) Maximum principal stress distribution on the upper surface (MPa). (b) Deflection distribution (m).

\subsection{Stability analysis based on safety thickness of $24 \mathrm{~m}$} The horizontal pillar has a complex shape, size, and lithology. As a result, both traditional methods and numerical modeling cannot adequately reflect the actual situation. To instruct the exploitation more efficiently, judging the safety thickness calculated via the new method is
In addition, in practical engineering applications, the contact region between the horizontal pillars and the surrounding wall or interval pillar is not clamped completely because rock mass has a certain flexibility, this is why the stress in the contact region is the largest. Eventually, however, the flexure happens in the center of the pillar. For LI Guanji iron mine, a lower safety factor $(f)$ of 1.2 is chosen to design the safety thickness of horizontal pillars because of the actual failure conditions occurring in the pillars and the pointed pillars left in the stope. Based on the most disadvantageous Pillar 6\#, the critical safety thickness should be $23.96 \mathrm{~m}$ for the whole pillars. Fig. 9 shows the maximum principal stress and deflection distribution of Pillar 6\#. In Fig. 9, the maximum value of the maximal principal stress appears on the edge side or the corner of the pillars and is respectively less than the tensile strength. The maximal deflection occurs in the center of the pillars in accordance with engineering experiences. necessary. Table 5 lists the critical safety thickness of 10 pillars on level $-320 \mathrm{~m}$ in LI Guanji iron mine calculated via the traditional methods (limit span mechanism, K.B.Lu Peinie equation, Plate beam equation, and PU's equilibrium arch) and the new method.

Table 5. The critical safety thickness of 10 pillars by the traditional methods and the new method 
Zhang Wen, Lian Minjie, Chen Yu, Liu Lang, Shi Guangbin and KI-IL Song/

Journal of Engineering Science and Technology Review 10 (5) (2017) 199-211

\begin{tabular}{|c|c|c|c|c|c|c|c|c|c|c|}
\hline \multirow[b]{2}{*}{ Method } & \multicolumn{10}{|c|}{ The critical safety thickness $T_{f}(\mathrm{~m})(f=1.2)$} \\
\hline & $1 \#$ & $2 \#$ & 3\# & $4 \#$ & $5 \#$ & 6\# & $7 \#$ & $8 \#$ & 9\# & $10 \#$ \\
\hline Limit span mechanism & 15.19 & 18.40 & 48.48 & 34.57 & 28.71 & 36.44 & 23.22 & 27.71 & 20.68 & 17.07 \\
\hline K.B.Lu peinie equation & 9.56 & 34.20 & 10.93 & 11.76 & 17.43 & 39.87 & 19.51 & 15.57 & 18.57 & 19.62 \\
\hline Plate beam equation & 18.50 & 35.56 & 19.82 & 20.59 & 25.20 & 38.44 & 26.70 & 23.78 & 26.04 & 26.78 \\
\hline PU's equilibrium arch & 17.60 & 17.94 & 20.96 & 19.61 & 19.02 & 19.80 & 18.46 & 18.92 & 18.19 & 17.80 \\
\hline New method & 7.66 & 11.06 & 19.55 & 15.37 & 15.78 & 23.96 & 12.86 & 15.50 & 11.35 & 8.70 \\
\hline
\end{tabular}

As illustrated in Table 5, the safety thickness of the horizontal pillar by the traditional methods are larger than that by the new method with a small span, whereas the safety thickness of the new method and PU's equilibrium arch are smaller with a long span. The safety thickness by the new method is much less than that of traditional methods without considering the support from the lower backfill. Under the same condition, compared with the traditional methods, the safety thickness of horizontal Pillar 6\# by the new method is $28.77 \%$ smaller than the average value. In terms of economy, the thickness of the pillar calculated by the new method can reduce the loss rate of the ore, but it necessitates stability analysis by numerical simulation to determine whether it meets the safety requirements.

\subsubsection{Scheme and numerical modeling of the horizontal pillars}

The mechanical upward horizontal slice stope-filling method with pointed pillars is adopted for LI Guanji iron mine. The stope arrangement is shown in Fig. 2. The width of the square pointed pillars is $5 \mathrm{~m}$, and the space is $15 \mathrm{~m} \times 15 \mathrm{~m}$. The width of the interval pillars between stopes is $6 \mathrm{~m}$. After the aforementioned finite element analysis, the safety thickness of horizontal pillars between level $-320 \mathrm{~m}$ and level $-220 \mathrm{~m}$ is obtained. When the safety factor $f$ is 1.2 , the thickness of pillars is $23.96 \mathrm{~m}$. In the actual project, the thickness of horizontal pillars is set as $24 \mathrm{~m}$, and the rationality of the thickness is verified using a $3 \mathrm{D}$ numerical model established by FLAC3D based on the site-specific geological and mining condition. The size of the model is $2000 \mathrm{~m}(x$-axis: $\mathrm{NW}) \times 600 \mathrm{~m}(y$-axis: $\mathrm{NE}) \times 565 \mathrm{~m}(z$-axis: vertical direction) in terms of length $\times$ width $\times$ height, with 990,542 six-node triangular elements and 166,949 grids. The model includes an ore body, hanging wall, footwall and backfill, all of which are assumed to conform to the MohrCoulomb yield criterion. The employed physico-mechanical parameters are listed in Table 1. To make the model more real and practical, the gradient-horizontal pressures and gravity stress are applied in the meshed numerical model, as shown in Eq. (15). The entire numerical calculation model and the geometry of mining infrastructure of stopes and pillars are shown in Figs.10 and 11.

$\left\{\begin{array}{l}\sigma_{h \max }=0.054 z+0.702 \\ \sigma_{h \min }=0.046 z+0.114 \\ \sigma_{z}=0.031 z\end{array}\right.$

where $z$ is the vertical height of the overlying strata, m; $\sigma_{h \max }$ is the maximum horizontal principal stress, MPa, which is consistent with the strike of ore body; $\sigma_{h \min }$ is the intermediate principal stress, $\mathrm{MPa}$; and $\sigma_{z}$ is the vertical stress, MPa.

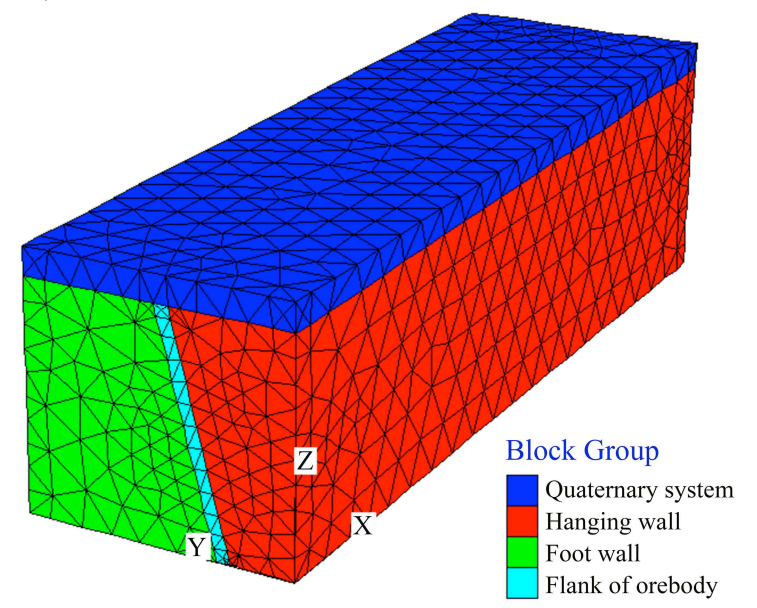

Fig. 10. 3D numerical model

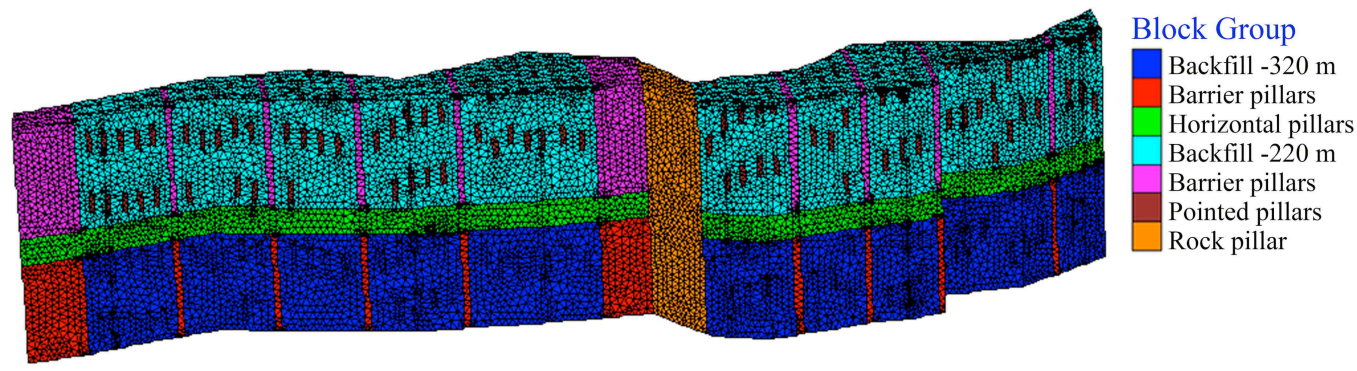

Fig. 11. Distribution of horizontal pillars and stopes

\subsubsection{Stability analysis of the horizontal pillars}

Results of the 3D numerical model are analyzed in terms of stress, displacement, and extent of plastic zones of the $24 \mathrm{~m}$ thick horizontal pillars. As demonstrated in Fig.12, both the maximum principal stress and tensile stress appear on the bottom of the horizontal pillars. Furthermore, the maximum principal stress of the pillars is compressive stress. The highest value is $53.16 \mathrm{MPa}$, which appears on the bottom of Pillar 7\# near the edge of Stope 7\#. The maximum tensile stress occurs in the center of the bottom surface of Pillar 3\#. The value of the highest tensile stress is $0.95 \mathrm{MPa}$, which does not exceed the ultimate tensile strength of the ore body. 


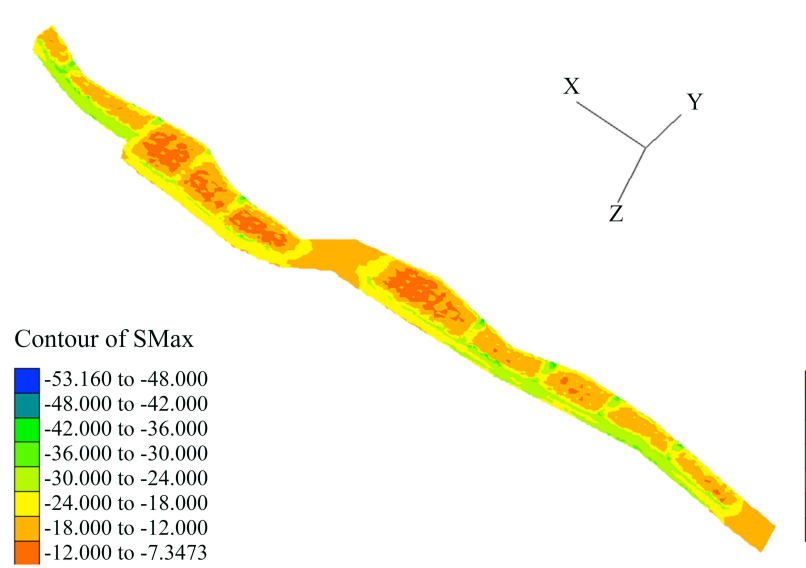

(a)

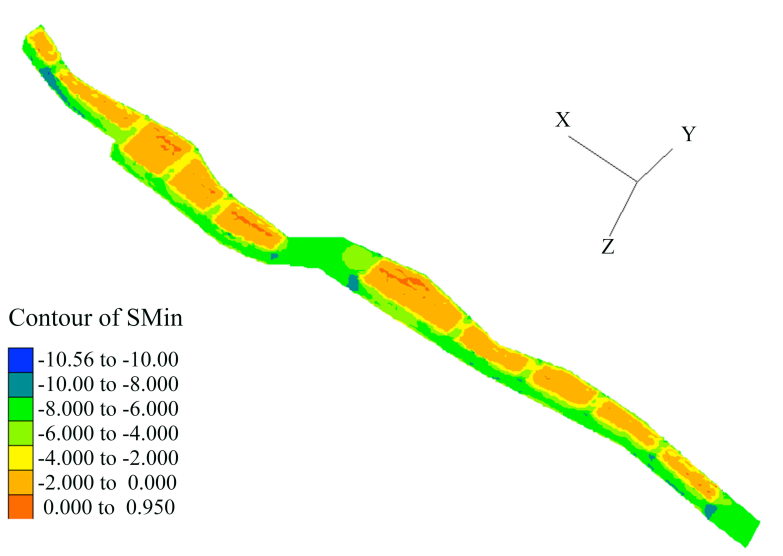

(b)

Fig. 12. Principal stress distribution of the $24 \mathrm{~m}$-thick horizontal pillars (MPa). (a) Maximum principal stress distribution. (b) Minimum principal stress distribution.

As shown in Fig. 13, the subsidence of the horizontal pillars is mainly bending instead of failure, and it changes gradually (i.e., no abrupt change) in the scope of each stope. The maximum displacement of the pillar at the top of each stope appears in the center of the horizontal pillar, and the maximum vertical displacement is $20.407 \mathrm{~mm}$, which appears in the center of Pillar 3\#. It can be concluded from Figs. 12 and 13 that the maximum tensile stress and subsidence occur in the center of the lower surface of Pillar $3 \#$, which is the most likely risk site for failure and collapse. Stope $3 \#$ is the second-largest stope with mined-out stopes on both sides, making it more dangerous than Stope 6\#, which has the largest area and one side near the big rock barrier pillar. This finding confirms that the thickness of the horizontal pillars is affected not only by the exposed area, but also by its shape and location.

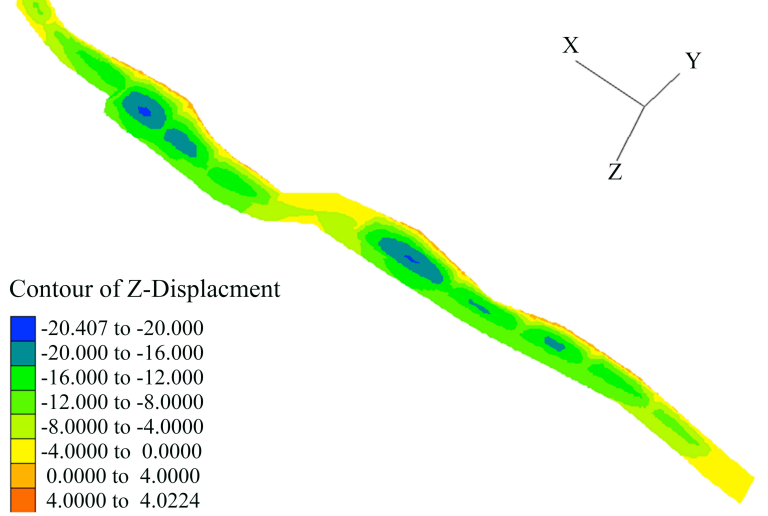

Fig. 13. Vertical displacement distribution of the horizontal pillars $(\mathrm{mm})$

Fig. 14 shows that the plastic or failure zones of the horizontal pillars appear after the excavation and backfill. In the simulation, local shear-slip damage occurs at the bottom of the pillar but with no large area of collapse. Therefore, the horizontal pillars with thickness of $24 \mathrm{~m}$ between level -320 $\mathrm{m}$ and level $-220 \mathrm{~m}$ and a working depth of $220 \mathrm{~m}$ are safe, stable, and break-less. The horizontal pillars working with backfill can also ensure the safety of production and the deformation of ground surface to a controllable range. Such deformation can not cause damage to the villages above the mine surface when the thickness of the horizontal pillar is 24 m.

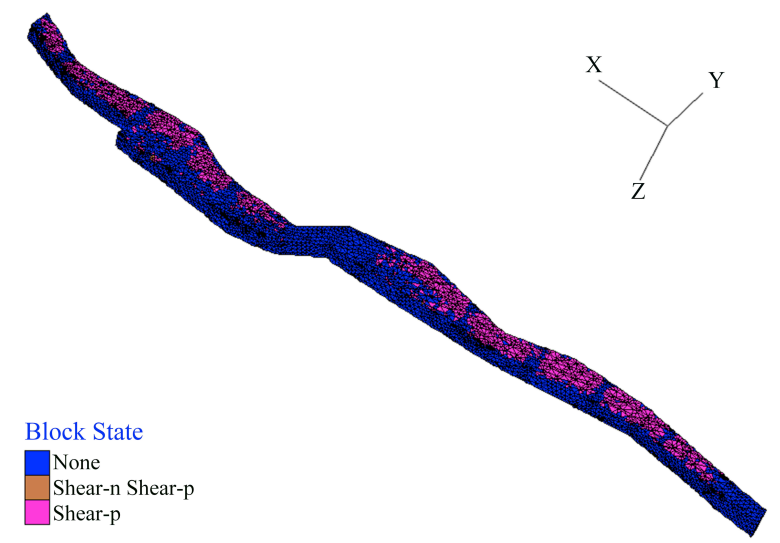

Fig. 14. Plastic zone distribution of the horizontal pillars

\section{Conclusions}

To evaluate the safety thickness accurately, an innovative method based on the adoption of the contact model in FEM was developed to estimate the safety thickness of the horizontal pillar, with consideration of both the overlying load from the upper backfill and the reaction from the lower backfill. A case study was analyzed to compare the safety thickness obtained by traditional and proposed methods. The following conclusions could be drawn:

(1) Under a large-scale and continuous mining environment, the horizontal pillars reserved in the backfill with reasonable safety thickness can effectively isolate the upper and lower levels, avoid cavity expansion, and reduce hazards such as rock burst and roof fall.

(2) Numerous factors affect the overlying backfill load, including ore body dip, friction and cohesion between the backfill and surrounding rock. According to the actual mining conditions, the mechanical model of the upper inclined backfill body should be built first. The calculation formula of load from the upper backfill acting on the top of the pillar can be deduced based on the characteristics of the backfill material and the geological conditions. The main affecting factors are considered synthetically, with the overlying load $q_{z}$ acting on the top of the pillar determined to be closer to the actual one and more reliable.

(3) In terms of the geological conditions, the horizontal pillars were analyzed with mechanics. The pillars were 
simplified as elastic plates with clamped edges. The reasonable analysis elements were chosen according to the actual situation. The interactions between the pillar and the backfill body were simulated by contact elements, and the finite element analysis models were built by ANSYS software. The models were used in the numerical computation of 10 horizontal pillars in LI Guanji iron mine. The results of finite element numerical simulation show that a certain functional relation exists between the pillar thickness and the maximum principal stress, as well as the deflection. Both the highest maximum principal stress and the deflection decrease greatly with thickness, an outcome that follows the power function.

(4) According to the capability and deformation of horizontal pillars, the maximum tensile stress criterion was chosen to determine the critical safety thickness. For LI Guanji iron mine, the critical safety thickness of 10 pillars was designed as $23.96 \mathrm{~m}$ considering the safety factor 1.2 . The $24 \mathrm{~m}$-thick horizontal pillars were applied to the subsequent exploitation in LI Guanji iron mine. To assess the safety thickness, the traditional methods and numerical modeling were compared. The safety thickness of the horizontal pillars by the new method was smaller. The results of $3 \mathrm{D}$ numerical modeling show that the maximum tensile stress is $0.95 \mathrm{MPa}$, which does not exceed the allowable tensile stress. The $z$-displacement is $20.407 \mathrm{~mm}$, which is in a reasonable range. The simulation results have verified the safety of the horizontal pillars with thickness of $24 \mathrm{~m}$, thus providing technical support to efficient safety large-scale continuous backfill mining.

Thus, theoretical analysis, mechanical model, and numerical modeling are utilized in this study. The combined action of the upper and lower backfill is considered in the proposed method to design the safety thickness of horizontal pillars more accurately. The result is applied to the subsequent exploitation of LI Guanji iron mine, meeting the requirements of safety production and encouraging enhanced economic benefit. This new method has important reference values in the thickness design of the horizontal pillars, which can be applied to similar mines with backfill mining. However, the safety thickness of pillars is influenced by many factors. Owing to all kinds of limited conditions, the proposed method cannot consider all possible factors, such as the horizontal stress from the surrounding rock and the inclination of the lower backfill. Therefore, more influencing factors should be considered in future studies.

\section{Acknowledgements}

The authors are grateful for the support provided by the Scientific Research Program funded by the Shaanxi Provincial Education Department (No. 17JK0455, 15JK1466); the National Natural Science Foundation of China (No. 51674188, 51604299, 51504182); China Postdoctoral Science Foundation (No.2015M582685, 2016M600636); the Natural Science Basic Research Plan of Shaanxi Province of China (No.2015JQ5187), and the Xi' an University of Science and Technology Research Fund Program for Young Scholars (No.2014-NY-018).

Access article distributed under the terms of the Creative Commons Attribution License

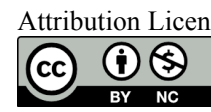

\section{References}

1. Chen, Q.F., Liu, Y.X., "Study on the size effect of goaf stability". Disaster Advances, 5, 2012, pp.1597-1601.

2. Choudhury, P.B., Raina, A.K., Ramulu, M., Chakraborty, A.K., Bandopadhyay, C., "Crown pillar stability assessment in an underground copper mine using acoustic emission". International Journal of Rock Mechanics \& Mining Sciences, 41(3), 2004, pp. $235-240$.

3. Zhang, P.H., Yang, T.H., Yu, Q.L., Xu, T., Zhu, W.C., Liu, H.L., Zhou, J.R., Zhao, Y.C., "Microseismicity induced by fault activation during the fracture process of a crown pillar". Rock Mechanics \& Rock Engineering, 48(4), 2015, pp.1673-1682.

4. Seryakov, V., "Calculation of stress-strain state for an over-goaf rock mass". Journal of Mining Science, 45(5), 2009, pp.420-436.

5. Bakhtavar, E., Oraee, K., Shahriar, K., "Determination of the optimum crown pillar thickness between open pit and block caving". In: 29th International Conference on Ground Control in Mining, Morgantown, USA: West Virginia University, 2010, pp.325-332.

6. Tawadrous, A.S., Katsabanis, P.D., "Prediction of surface crown pillar stability using artificial neural networks". International Journal for Numerical and Analytical Methods in Geomechanics, 31, 2007, pp.917-931.

7. Swift, G.M., Reddish, D.J, "Stability problems associated with an abandoned ironstone mine". Bulletin of Engineering Geology and the Environment, 61(3), 2002, pp.227-239.

8. Nomikos, P.P., Sofianos, A.I., Tsoutrelis, C.E., "Structural response of vertically multi-jointed roof rock beams". International Journal of Rock Mechanics \& Mining Sciences, 39(1), 2002, pp.79-94.

9. Hutchinson, D.J., Phillips, C., Cascante, G., "Risk considerations for crown pillar stability assessment for mine closure planning". Geotechnical \& Geological Engineering, 20(1), 2002, pp.41-63.
10. Sun, S., Liu, W., Zhang, Y., "The safe thickness of top plate in the process of the underground excavation transferred to opencast excavation". In: International Symposium on Energy Science and Chemical Engineering, Guangzhou, China: IEEE, 2015, pp.124129.

11. Zhang, J., Jiang, F., Zhu, S., Zhang, L., "Width design for gobs and isolated coal pillars based on overall burst-instability prevention in coal mines". Journal of Rock Mechanics and Geotechnical Engineering, 8(4), 2016, pp.551-558.

12. Chang, J., Zhang, J.H., Zhang, D.J., Liu, Z.J., "Study of methods for determining the of safe roof in open casting turn to underground mining”. Applied Mechanics \& Materials, 2935(484), 2014, pp.484-485: 589-592.

13. Zhao, X.D. , "Stability analysis of insulating pillar of excavation of Chambishi copper mine in depth". Chinese Journal of Rock Mechanics and Engineering, supp11, 2010, pp.2616-2622.

14. Singh, G.S.P., Singh, U.K., Murthy, V.M.S.R., "Application of numerical modeling for strata control in mines". Geotechnical and Geological Engineering, 28, 2010, pp.513-524.

15. Georgieva, T., Anastasov, D., Gyrkov, I., "Crown pillar behavior study using numerical modeling in Chelopech mine". In: Rock Mechanics and Rock Engineering: From the Past to the Future, London, England: CRC Press, 2016, pp.457-461.

16. Kumar, H., Deb, D., Chakravarty, D., "Numerical analysis of sill and crown pillar stability for multilevel cut and fill stopes in different geomining conditions". Geotechnical \& Geological Engineering, 34(2), 2016, pp.529-549.

17. Szwedzicki, T., "Pre- and post-failure ground behaviour: case studies of surface crown pillar collapse". International Journal of Rock Mechanics \& Mining Sciences, 36(3), 1999, pp.351-359.

18. Glazer, S.N., Hepworth, N., "Crown pillar failure mechanism-case study based on seismic data from Palabora Mine". Transactions of the Institution of Mining \& Metallurgy, 115(2), 2006, pp.75-84. 
Zhang Wen, Lian Minjie, Chen Yu, Liu Lang, Shi Guangbin and KI-IL Song/

Journal of Engineering Science and Technology Review 10 (5) (2017) 199-211

19. Palchik, V., "Influence of physical characteristics of weak rock mass on height of caved zone over abandoned subsurface coal mines". Environmental Geology, 42(1), 2002, pp.92-101.

20. Liu, Y.Z., Deng, L., Wang, Q.F., Zhao, W., Shi, Z.J., Zhang, Q., Zhang, B.T., "Study on top pillar size of transition stope from caving method to filling method based on $\pi$ theorems". Journal of Mining \& Safety Engineering, 32(2), 2015, pp.331-336.

21. Carter, T.G., "A new approach to surface crown pillar design". In: 16th Canadian rock mechanics symposium, Sudbury, Canada: Laurentian University, 1992, pp.75-84.

22. Hoek, E., Brown, E.T., "Excavation in Rock". London: Underground Institution of Mining and Metallurgy, 1980.

23. Saadatpour, M. M., Azhari, M., "The Galerkin method for static analysis of simply supported plates of general shape". Computers \& structures, 69(1), 1998, pp.1-9.

24. Kang, S.W., Atluri, S.N., "Free vibration analysis of arbitrarily shaped polygonal plates with simply supported edges using a subdomain method". Journal of Sound and Vibration, 327(3), 2009, pp.271-284.

25. Guo, W., Wang, H., Liu, Z., "Coal pillar stability and surface movement characteristics of deep wide strip pillar mining”. Journal of Mining \& Safety Engineering, 32(3), 2015, pp.369-375.

26. Li, X.B., Li, D.Y., Liu, Z.X., Zhao, G.Y., Wang, W.H., "Determination of the minimum thickness of crown pillar for safe exploitation of a subsea gold mine based on numerical modelling". International Journal of Rock Mechanics \& Mining Sciences, 57, 2013, pp.42-56.

27. Mindlin, R.D., "Influence of rotary inertia and shear on flexural motions of isotropic, elastic plates". Journal of Applied Mechanics, 18,1951, pp.31-38.
28. Tsai, C.C., Wu, M.Y., " Analytical particular solutions of augmented polyharmonic spline associated with Mindlin plate model". Numerical Methods for Partial Differential Equations, 28(6), 2012, pp.1778-1793.

29. Safarian, S.S., Harris, E.C., "Design and construction of silos and bunkers". New York: Van Nostrand Reinhold Company Inc., 1985.

30. Aubertin, M., Li, L., Arnoldi, S., Simon, R., "Interaction between backfill and rock mass in narrow stopes". Soil and Rock America, 1, 2003, pp.1157-1164.

31. Belem, T., Harvey, A., Simon, R., Aubertin M., "Measurement and prediction of internal stresses in an underground opening during its filling with cemented fill". In: Proceedings of the 5th Int. Symp. on Ground support in Mining and Underground Construction, Perth, Australia: CRC Press, 2004, pp. 619-630.

32. Huang, Z.G., Dai, X.G., Dong, L.J., "Buckling failures of reserved thin pillars under the combined action of in-plane and lateral hydrostatic compressive forces". Computers \& Geotechnics, 87, 2017, pp.128-138.

33. Zhuravkov, M.A., Krupoderov, A.V., "Dynamic load effect in the vicinity of goafs within rock masses". Journal of Mining Science, 46(3), 2010, pp.241-249.

34. Susila, E., Anggraini, N., "Soil-structure interaction of a piled raft foundation in clay-a 3D numerical study". Journal of Engineering \& Technological Sciences, 48 (4), 2016, pp.388-407.

35. Reddy, J.N., "Theory and Analysis of Elastic Plates and Shells". New York: CRC Press, 2007.

36. Dhatt, G., Touzot, G., Lefrancois, E., "Finite Element Method". New York: John Wiley \& Sons Inc Press, 2012.

37. Jiang, J.J., He, F.L., He, Y.B., "Finite Element Method and Application". Beijing: Chinese Machine Press, 2006.

38. Moaveni, S., "Finite element analysis: theory and application with ANSYS". London: Pearson Education, Inc., 2007. 